\title{
EVOLUCIÓN HISTÓRICA Y EDUCATIVA DEL DEPORTE FEMENINO. UNA FORMA DE EXCLUSIÓN SOCIAL Y CULTURAL
}

\section{Belén Zapico Robles}

bzapr@unileon.es

Universidad de León
Concepción E. Tuero del Prado socio-cultural.cetuep@unileon.es

Universidad de León

Recibido: 28-02-2014

Aceptado: 07-04-2014

\section{Resumen:}

Uno de los elementos más característicos de nuestra sociedad en relación a la diferenciación y desigualdad de la mujer en el ámbito del deporte es el lenguaje en todas sus facetas comunicativas: escrito, verbal, icónico, etc. y es lo que puede contribuir de forma evidente a promocionar un cambio sustancial en el contexto del deporte femenino. Sin embargo, para esbozar la configuración del deporte femenino es necesario recurrir a una perspectiva históricoeducativo, que nos permita reflexionar sobre la persistencia de los estereotipos arraigados en nuestra realidad social y cultural. La finalidad de este trabajo es reflexionar sobre factores diversos (históricos, sociales, culturales y educativos) que evidencian la desigualdad en torno al género en el ámbito del deporte.

Palabras Clave: Desigualdad de género, deporte, mujer, educación física, medios de comunicación.

\begin{abstract}
:
Language, whether written, verbal, iconic, etc., is one of the most characteristic elements of contemporary society in relation to the differentiation and inequality of women in sport, and could make a considerable contribution to promoting a substantial change in women's sports. However, in order to describe the evolution of women's sports, it is necessary to employ a historical and educational perspective that will enable a consideration of the persistence of deeply-rooted stereotypes in contemporary society and culture. The aim of this paper is to discuss various factors of a historical, social, cultural and educational nature which shed light on gender inequality in sport.
\end{abstract}

Keywords: Gender inequality, sport, women, physical education, mass media. 


\section{Introducción}

Debemos aceptar que la complejidad de la realidad social deportiva para su análisis radica, en buena medida, en su fuerza expansiva y globalizadora, lo cual ha contribuido a convertirlo no sólo en una práctica cotidiana sino también en un estilo de vida que cuenta con el seguimiento de un gran número de personas. De ahí que haya ido desarrollando un carácter abierto, heterogéneo y diversificado para los diferentes intereses de los segmentos de población (Lagardera, 2009). En la misma línea ya se posicionaba Cagigal (1981) cuando decía que el deporte se estaba convirtiendo en un fenómeno social totalmente vinculado a las diferentes manifestaciones culturales que caracterizan a la sociedad.

En el ámbito educativo y cultural hay suficientes evidencias que muestran la existencia de desigualdades desde la perspectiva de género y que desde hace tiempo, han servido para llevar a cabo en muchos casos una consensuada estratificación a este respecto. Estas manifestaciones se remontan a épocas históricamente más antiguas donde el deporte ya era considerado un reducto para hombres, en el cual las mujeres no tenían cabida. Así, en Grecia solo había participación masculina en los Juegos Olímpicos y más adelante, con las primeras olimpiadas modernas la situación se mantenía, ya que Pierre de Coubertinlas excluyó de las mismas argumentando que las mujeres no estaban preparadas para la práctica deportiva (Pérez Triviño, 2011: 95). En la misma línea recoge Molina (20013) los argumentos cargados de matices paternalistas y sexistas que se esgrimen en épocas muy actuales haciendo referencia a la desfeminización de las mujeres, ya que el ejercicio físico contribuye a la pérdida de belleza y fertilidad. Es curiosa esta argumentación si tenemos en cuenta que las mujeres también desarrollan otras prácticas y hábitos en diferentes ámbitos de la vida social en los que pueden poner en peligro su salud en mayor medida (determinadas profesiones, actividades lúdicas, hábitos, etc.).

Desde este punto de vista, no resulta nada extraño que también en el contexto deportivo se puedan apreciar estas desigualdades, impidiendo un desarrollo coeducativo y cultural igualitario entre hombres y mujeres. Así, el deporte en general, suele estar unido a unas actitudes y valores que desde un criterio estereotipado se presuponen al género masculino. No debemos olvidar la importancia que tienen las tradiciones y los modelos culturales en todos los ámbitos de nuestra vida, incluido el deporte, y que hacen que poco a poco se vayan incorporando al desarrollo de la identidad personal y social (Blanchard y Cheska, 1986). 
Se asocian al deporte valores tradicionalmente considerados como masculinos, motivo por el que muchas mujeres, si no han tenido una socialización deportiva inicial, no se sentirán atraídas por el mismo (García Ferrando, 2006), seguramente porque estas prácticas pueden ir en contra de sus hábitos y representaciones corporales. Se trata de mecanismos generados en el seno de la familia, como apuntan Mosquera y Puig (2009), que paulatinamente van generando la decantación hacia ciertos modelos de prácticas.

La familia como agente de socialización clave, es donde primeramente se transmite esta influencia desigual entre niños y niñas con respecto a la inclinación o interés hacia el deporte. Los niños se identifican de forma muy rápida y clara con la figura paterna y utilizando la terminología de Bourdieu (1988), adquieren el habitus deportivo que contribuye a reforzar aún más los procesos de diferenciación y distinción social. En el caso de las niñas, esta identificación puede suponer con cierta asiduidad una ruptura con el contexto femenino representado por la figura materna, la cual se convierte en modelo de imitación y refuerzo para la niña.

La finalidad que hemos planteado en este trabajo es reflexionar sobre factores diversos (históricos, sociales, culturales y educativos) que evidencian la desigualdad en torno al género en el ámbito del deporte. Para su consecución, nos hemos planteado una breve descripción de puntuales hechos históricos, y de períodos cronológicos de gran incidencia en la realidad femenina tanto en el deporte como en la educación física. Además, otro de los objetivos que pretendemos con este trabajo es recoger una serie de propuestas encaminadas a reparar esta desigualdad, implicando a los diferentes agentes sociales que son corresponsables de su mantenimiento. Todo ello orientado a conseguir una disminución de los obstáculos que se puedan encontrar las mujeres que practican deporte para facilitarles un desarrollo personal más igualitario. De esta forma se plasman múltiples actitudes sexistas que se manifiestan en diferentes ámbitos y que influyen en la dinámica social y cultural.

Dentro del panorama deportivo femenino y con la colaboración de estos agentes sociales se produce un proceso de "trivialización" (Léséluc et al., 2009:87) en el sentido de que se desvían los aspectos puramente deportivos como el logro, el rendimiento, el entrenamiento, etc. hacia aspectos relacionados con la familia, la vida cotidiana e incluso relaciones fuera del contexto deportivo de la atleta. De esta manera, queda en evidencia que la incorporación de la mujer al deporte se ha hecho en función de las pautas marcadas por el modelo de imitación masculino: los éxitos, los entrenamientos, las marcas, las reglas, las referencias utilizadas por los medios de comunicación, etc. 
Finalmente, se recogen una serie de propuesta con el fin de contribuir al conocimiento, difusión y visibilización de la posición que ocupan las mujeres en la educación física y el deporte. Así, no debemos descartar las aportaciones de los valores deportivos femeninos hacia la sociedad actual.

\section{La práctica físico-deportiva de las mujeres en las civilizaciones antiguas y la restauración del olimpismo moderno: germen del fenómeno social deportivo}

Tal y como se entiende en la actualidad el deporte, éste deriva del sport británico gestado en el siglo XIX. Bourdieu (1993) citado por Águila (2008: 23) “explica la génesis del deporte a partir de las necesidades educativas de las clases sociales dominantes y del significado original con que se concibió la práctica. La transición de los juegos populares a los deportes se produjo en el seno de las PublicSchool inglesas, instituciones educativas masculinas de la aristocracia y la alta burguesía". Sin embargo, es necesario echar una mirada hacia las civilizaciones clásicas para determinar la incorporación de la mujer en el deporte, matizando las peculiaridades de la práctica física en estas civilizaciones antiguas respecto al concepto actual de deporte. Así, reconoce García Romero (2005: 9-10) que la Antigüedad grecolatina:

"ha sido quizá la única etapa de nuestra historia en la que el deporte y la práctica de ejercicios físicos han alcanzado una importancia social, política, cultural y económica en cierto modo comparable con el deporte actual... los agones griegos y sobre todo y muy especialmente los ludi y manera romanos ofrecen claros precedentes para algunos aspectos claves del deporte moderno".

Por tanto, parece necesario revisar el papel de la mujer en el ámbito de la actividad físicodeportiva en este período, no solo para evidenciar su papel en este marco, sino también porque estas civilizaciones clásicas han sido el germen de una de las manifestaciones deportivas por excelencia en nuestros días, los Juegos Olímpicos.

Los estudios sobre este período indican que es escasa la documentación disponible sobre la participación de las mujeres en la actividad físico-deportiva en Grecia y Roma. No obstante, expondremos brevemente algunos retazos de esta participación femenina a modo de somera representación. Asimismo, es necesario partir de una interpretación diferente de la práctica físico- 
deportiva entre ambas civilizaciones. En el caso de Grecia, argumenta Cascón (2005) que los juegos funerarios y las competiciones estaban reservados para los estratos sociales más altos, mientras que el pueblo actuaba como espectador, tal y como se deduce de la obra homérica. Además destaca la relevancia que para los griegos tenía "su apariencia atlética y su capacidad para competir” (Cascón, 2005: 157). Sin embargo en el caso de Roma, el espectáculo era el factor esencial, y los dirigentes romanos se ocupaban fundamentalmente de la financiación y gestión de estos espectáculos, relegando cualquier atisbo de demostración de sus virtudes atléticas. Así, insiste el autor que "en Roma el deporte es sobre todo espectáculo, en Grecia es participación” (Cascón, 2005: 169).En Grecia, Pastor y Aguilera (2007: 35) citando a Arrigoni (1985) señalan que "la actividad deportiva de las mujeres continuó ligada durante mucho tiempo al ámbito religioso o cultural", y esto determinó que la mujer no tuviera acceso a la práctica profesional, contrariamente al caso del deporte masculino que pronto debilitó "los lazos que unían deporte y culto" (García Romero, 2005: 179). Fuentes arqueológicas sitúan en Creta los primeros testimonios de participación femenina, concretamente en las actividades de salto del toro cretense y la danza, si bien una vez esposadas, las muchachas cretenses abandonaban estas actividades. En la obra homérica, se detallan en algunos pasajes juegos de pelota practicados por algunas de las protagonistas, que serían a la postre una de las actividades favoritas no solo por las griegas sino también por las mujeres romanas. García Romero (2005) destaca como en la época helenística y romana, la presencia femenina fue incrementándose, llegando a ocupar las mujeres el cargo de gimnasiarca (equivalente al actual concejal de deportes).

En el marco religioso - estrechamente vinculado a los juegos funerarios -, y con el objetivo de seleccionar sacerdotisas, se celebraba entre doncellas espartanas una carrera en honor a Dionisio, celebrándose en el dromos (carrera del estadio), sin espectadores masculinos. Indican Pastor y Aguilera (2007), que la carrera era el ejercicio físico más practicado por las mujeres griegas. Y por tanto debemos mencionar, a modo de réplica de los Juegos Olímpicos en los que las mujeres tenían prohibido el acceso incluso como espectadoras con penas de muerte si infringían la prohibición (Pastor y Aguilera, 2007), los Juegos Hereos en honor a la diosa Hera, celebrados en el santuario de Olimpia, también cada cuatro años, tal y como describe Pausanias. La competición consistía en una carrera entre dieciséis mujeres, se les asignaba el estadio olímpico, aunque la carrera se reducía a la sexta parte, eran premiadas con coronas de olivo, existía un colegio de jueces también de dieciséis mujeres, y se identifican estos juegos con un ritual de carácter prematrimonial (Arrigoni, 1985, citado por Pastor y Aguilera, 2007: 44), en el 
que "la carrera representaba la huida, la vida salvaje de las muchachas antes de ser domesticadas para el matrimonio" (García Romero, 2005: 192).

Respecto a Roma, señalábamos anteriormente que una de las actividades más populares entre las mujeres era el juego de la pelota, y existen ciertos testimonios de carreras reservadas a hijas de magistrados en las proximidades de Nápoles, aunque "debían ser de entretenimiento social y no de alta competición" (Pastor y Aguilera, 2007: 50). Historiadores clásicos, como Marcial y Tácito, recriminaban el interés de las mujeres en los espectáculos romanos cuestionando su afición desmesurada por los gladiadores o su participación activa en determinados espectáculos, aunque se considera que éstos últimos eran parodias o espectáculos jocosos (Pastor y Aguilera, 2007). Otra manifestación física relevante en la época romana, fueron las termas, edificios emblemáticos, comparados a las palestras griegas, y que estaban destinados para la socialización, la diversión y el ocio (Cascón, 2005), incluyendo distintas dependencias para los baños, para la ejercitación física y para la natación. Durante algunos períodos los baños eran mixtos, generando conflictos y escándalos relacionados con el pudor y la moral, y ante esto se establecieron horarios diferenciados para los baños de los hombres y los baños de las mujeres. La presión del cristianismo prohibió definitivamente el baño de las mujeres en el Concilio de Laodicea, en el año 320 d.C. (Malissard, 1996).

Una de las significativas diferencias entre Grecia y Roma ha sido que las mujeres griegas no podían acudir a los estadios olímpicos (existe cierto debate sobre si tan solo estaba permitido asistir a las doncellas), mientras que las mujeres etruscas y romanas no tenían ningún tipo de prohibición en acudir a cualquier espectáculo o a los eventos ofrecidos en el circo. Tal y como califican Pastor y Aguilera (2007), la participación de las mujeres en los grandes eventos deportivos en Grecia y en Roma fue puntual y anecdótica. Efectuando un salto en el tiempo, y remontándonos a los primeros Juegos Olímpicos de la era moderna, García Romero (2005) señala que numerosos prejuicios de la época clásica se trasladaron hasta el inicio del olimpismo impulsado por el barón Pierre de Coubertin, quien afirmaba que el papel que debía desempeñar la mujer en este acontecimiento "era el de coronar al vencedor" (García Romero, 2005: 178). No obstante, García Manso (2010: 139) atribuye esta frase al contexto sociocultural de finales del siglo XIX, en cuanto que "la mujer estaba relegada a un papel secundario en el mundo del deporte y su incorporación no era vista con agrado ni por la sociedad ni por los padres del Movimiento Olímpico moderno". De hecho, las mujeres quedarían fuera de la primera edición de los Juegos Olímpicos de la era moderna celebrados en Atenas en 1896, no sin reivindicativas 
deportistas, como la atleta local StamatiRevithi, que ante la prohibición de participar en este evento, decidió realizar el tradicional trayecto de la carrera de maratón por su cuenta (40 km. Entre las ciudades de Maratón y Atenas), su carrera extraoficial tuvo gran impacto entonces, aún a pesar de estar fuera del programa oficial (Buitrón y del Riego, 2004). Ya en la segunda edición, celebrada en París en 1900, las mujeres comienzan su participación de forma oficial en modalidades diversas como el tenis, golf y croquet. García Manso (2010) recoge en la siguiente tabla los datos relativos a la participación femenina en las primeras ediciones de los Juegos Olímpicos de la era moderna, pero quizás el dato más interesante se refiera a la comparación entre la participación femenina y masculina, y las notables diferencias de las ediciones correspondientes desde finales del siglo XX y los inicios del XXI.

Tabla 1. Datos sobre participación femenina en los JJOO de la era moderna

\begin{tabular}{|l|c|c|c|c|c|}
\hline JJOO-Ciudad & Año & Hombres & Mujeres & \% Mujeres & Países \\
\hline Atenas & 1896 & 241 & 0 & $0 \%$ & 14 \\
\hline París & 1900 & 1206 & 19 & $1.6 \%$ & 24 \\
\hline San Louis & 1904 & 681 & 8 & $1.2 \%$ & 13 \\
\hline Londres & 1908 & 1999 & 37 & $1.8 \%$ & 22 \\
\hline Estocolmo & 1912 & 2490 & 57 & $2.3 \%$ & 28 \\
\hline Amberes & 1920 & 2591 & 78 & $2.9 \%$ & 29 \\
\hline \multicolumn{5}{|l|}{} \\
\hline Seúl & 1988 & 6279 & 2186 & $25.9 \%$ & 159 \\
\hline Barcelona & 1992 & 6659 & 2708 & $28.9 \%$ & 169 \\
\hline Atlanta & 1996 & 6797 & 3523 & $34.1 \%$ & 197 \\
\hline Sydney & 2000 & 6582 & 4069 & $38.2 \%$ & 199 \\
\hline Atenas & 2004 & 6296 & 4329 & $40.7 \%$ & 202 \\
\hline Pekín & 2008 & 6450 & 4746 & $42.4 \%$ & 204 \\
\hline Londres & 2012 & 5864 & 4659 & $44.2 \%$ & 204 \\
\hline
\end{tabular}

Fuente: adaptado de García Manso, 2010.

Aunque en la Carta Olímpica publicada en 1994 por el COI (Comité Olímpico Internacional) se incluye la necesidad de articular los medios necesarios para promocionar la participación femenina, con el anhelo de la aplicación estricta del principio de igualdad entre hombre y mujeres, en la última edición celebrada en Londres, algunos países acudieron aún sin representación femenina. En la tabla 1, sin duda se puede constatar que, la inclusión femenina en el magnífico escaparate del deporte a nivel mundial, como es el caso de la celebración de unos Juegos Olímpicos, muy a finales del siglo XX, comienza a incrementarse superando el 
30\% de los atletas en la edición de 1996 hasta alcanzar un 44\% en la última edición de Londres.

La perspectiva de la presencia de las mujeres en el deporte, en este caso tomando como nexo común los orígenes del olimpismo en la Grecia clásica y su reinterpretación en la historia reciente, podría identificarse con la frase que Moran (2013) atribuye al éxito de la mujer en cualquier ámbito puesto que, según la célebre autora inglesa, "hemos tardado cien mil largos, lentos y arduos años en salir del patriarcado" (Moran, 2013: 306). Nuestra realidad, tal y como se abordará en el transcurso de este trabajo es que estamos ante un ámbito masculinizado. Tal es así, que la sentencia de García Romero atribuida al deporte femenino en la antigua Grecia bien puede reflejar la realidad actual,..."pues con demasiada frecuencia las alusiones a las féminas deportistas se limitan a su mención como una curiosidad, como algo pintoresco..." (García Romero, 1992: 104).

\section{La práctica física en el marco educativo}

En la temática que estamos abordando, debemos detenernos brevemente en el ámbito educativo, en el cual distintos datos evidencian las diferencias del género desde los primeros conatos de la educación física, o manifestaciones físicas en el marco educativo.

Así, es necesario reseñar, ya que incidirá en el rol de la mujer en las manifestaciones físicas de la época, el valor social asignado a la práctica física en el contexto educativo en las civilizaciones clásicas. En el caso de la antigua Grecia, se han reflejado singularidades entre Esparta y Atenas, pues "en el sistema educativo espartano el entrenamiento físico primaba sobre el intelectual" (García Romero, 2005: 182). Indudablemente, la militarización de la sociedad espartana condicionaba la educación, cuya peculiaridad esencial era que incluía a las mujeres. La importancia de la ejercitación física en este marco educativa ha sido ilustrada por diversas fuentes, y en algunos casos se señala, que la desnudez y la inclusión de la participación de las espartanas junto con los varones tenía “objetivos erótico-políticos, tras la aparente igual de sexos" (Cascón, 2005: 161), pretendiéndose la estimulación de los jóvenes. Pero algunas fuentes amplían este carácter utilitario del ejercicio físico en las espartanas con otros fines: soportar el parto, dar a luz hijos fuertes y sanos, desarrollar fácilmente las tareas domésticas como moler o transportar agua (Pastor y Aguilera, 2007). Se deduce de ciertas 
fuentes documentales que las jóvenes espartanas se ejercitaban con las mismas actividades físicas que los hombres (carrera, lucha, salto, lanzamiento, natación y equitación), a excepción del pancracio y el pugilato. Las mujeres atenienses, sin embargo, estaban excluidas de la práctica física en el marco educativo. Por el contrario, la educación en Roma no era una cuestión de Estado ya que recaía sobre las familias, y se pretendía la búsqueda de un buen soldado más que un atleta como se pretendía en Grecia, por tanto el carácter utilitarista de la práctica física estaba condicionado por la preparación para la guerra.

La relación de la mujer con la práctica física en un contexto educativo es prácticamente irrelevante hasta la aparición de las escuelas gimnásticas del siglo XIX que evolucionarán hacia los movimiento relevantes del siglo $\mathrm{XX}$, en los que predominan conceptos como la naturalidad del movimiento y el ritmo entre otros (Díez García, 2006).

Ya en referencia a los acontecimientos en España, Zagalaz (2001) sintetiza el devenir de la educación física y la mujer, así como otras manifestaciones físicas, durante el siglo XX de la siguiente forma ..."salvo el paréntesis de la II República, donde la educación presenta las características de gratuidad, laicismo y coeducación, que la harán diferentes a épocas anteriores y posteriores, con el inicio de la guerra civil y la instauración de la dictadura, continúa la separación de sexos, la discriminación de la mujer y el abandono de la Educación Física, que no recibirá el tratamiento que le corresponde hasta finales del siglo XX'(Zagalaz, 2001:7). Asimismo, Caspistegui (2006) considera que la presencia femenina en la práctica física es prácticamente nula hasta 1931, y si bien su trabajo se contextualiza en las sociedad vasconavarra, reseña una percepción transferible al resto del territorio español, pues tomando como referencia la guerra civil, indica este autor que hasta entonces las iniciativas deportivas surgían de la sociedad, y una vez finalizada la contienda, "el impulso deportivo procedió del nuevo entramado estatal y con una clara finalidad propagandística y de control social" (Caspistegui, 2006:254-255). De hecho, durante el franquismo, los condicionantes socio-políticos gestaron una asignación de valores concretos a ambos géneros, en términos generales se estableció la esfera pública consignada al hombre, y el ámbito privado a la mujer (Manrique, Torrego, López y Monjas, 2009). Si matizamos esta última afirmación, "para la sociedad franquista el lugar de la mujer era el hogar, desde donde debía difundir los valores y las pautas de comportamiento establecidos, criando y educando a sus hijos e hijas", tal y como reconocen Ramírez y Piedra (2011: 69).En torno a estos valores, se articuló el sistema educativo, en el que se mantuvieron las diferencias por razones de género, y evidentemente se significó en la 
materia de Educación Física. Los tres pilares que sustentaron el planteamiento de una educación física femenina, durante este período, se articularon en torno a la Sección Femenina - en vigencia entre 1934 y 1977 -, eran la postura científico-médica, la postura religiosa o nacionalcatolicismo y la postura política o nacionalsindicalismo (Manrique, Torrego, López y Monjas, 2009). El período franquista afianzó las diferencias significativas de los contenidos educativos de la Educación Física femenina frente a la masculina, así los las Enseñanzas del Hogar y la Formación del Espíritu Nacional se anteponían a la Educación Física en el caso de las estudiantes (Zagalaz, 2001). La Sección Femenina no solo se erigió como "agente socializador primario" sino que además "se convirtió en el referente máximo en cuanto a la labor formativa a realizar con la mujer" (Manrique, Torrego, López y Monjas, 2009: 8). Los estereotipos establecidos por la moral y el espíritu cristiano durante este período determinaron "los deportes ideales desde una perspectiva técnica y moral: gimnasia, danza (uniendo la clásica a las folclóricas), ritmo y cinco deportes: esquí, natación, hockey, balonmano y baloncesto" (Zagalaz, 2001: 11). Estos contenidos se articulaban en torno a una de las mayores preocupaciones, y era que la mujer no debía "poner en riego la función procreadora para la que había sido destinada" (Manrique, Torrego, López y Monjas, 2009: 10). Prosiguen estos autores destacando que durante este período, y a pesar del empeño de las dirigentes de la Sección Femenina, la inclusión de la Educación Física y el deporte en el proceso formativo de las mujeres se realizó de forma parcial y "dominado por intereses de carácter ideológico y religioso", cuestionándose además si se "siguen manteniendo algunas de las características que definieron la Educación Física femenina en el franquismo en la Educación Física actual” (Manrique, Torrego, López y Monjas, 2009: 13).

En todo caso, y a pesar de estas posibles influencias del período predemocrático en nuestro país, "en el campo de la educación física y el deporte la mujer de hoy día no busca la igualdad con el hombre, sino la definición de un modelo corporal propio, autónomo y respetado, con sus propias actividades físico-deportivas que partan de su propia naturaleza y no se compare con el ámbito masculino" (Ramírez y Piedra, 2011: 69). Asimismo, los estereotipos deportivos de género se recogen en estudios al respecto, persistiendo en el marco educativo (Blández, Fernández y Sierra, 2007). Y es precisamente en esta última investigación, realizada con escolares de Educación Primaria y Secundaria, uno de los ejemplo que refleja como las actividades físico-deportivas son percibidas hacia un género u otro en función de determinados rasgos, así las caracterizadas como activas, agresivas y violentas (rugby, fútbol, boxeo, kárate y 
motociclismo) serían masculinas, y aquellas caracterizadas por la tranquilidad, expresión, ritmo, flexibilidad, elasticidad y coordinación (yoga, aerobic, ballet, gimnasia rítmica y voleibol) serían femeninas. En un estudio posterior, se corroboran también estos planteamientos, pero se añade que "las niñas sí que practican deportes encasillados en el estereotipo masculino, como el fútbol o deportes de combate. Este hecho está en consonancia con la investigación que indica un mayor impacto de los estereotipos sobre los niños que sobre las niñas" (Ruíz Tendero, 2011: 28). Coinciden los expertos en señalar que "las pautas de igualdad deportiva que en la escuela más o menos se mantienen, se cortan en la preadolescencia y se pierden en la adolescencia” (Santos y Balibrea, 2004: 414).

Si bien se han puesto en marcha planes o programas para implantar la igualdad en la escuela, tal y como se observará en el siguiente apartado, el deporte en términos generales difunde valores masculinos. En este sentido prosiguen Santos y Balibrea (2004: 413) destacando que "los medios de comunicación y los intereses del deporte-espectáculo insisten en exhibir la fuerza física, en sobredimensionar la competitividad, en lucir el choque físico como expresiones glorificadas del deporte", y es precisamente la competitividad un rasgo alejado de los valores femeninos, y que pudiera ser uno de los motivos por los que desde los medios de comunicación se genere escaso interés al respecto.

\section{El lenguaje como instrumento generador de actitudes sexistas en el ámbito deportivo}

El lenguaje deportivo refleja claramente estas referencias históricas y culturales del modelo tradicional masculino, a las que antes hemos aludido, así como "los estereotipos asociados al género que aparecen plasmados en muchas acepciones androcéntricas y sexistas" (Alfaro, Bengoechea y Vázquez, 2010: 23). Estas representaciones o clichés mentales simplificadoras se transmiten muy fácilmente y resultan muy resistentes al cambio ya que como afirma Puig (2009), las relaciones de género están dominadas por los hombres en el marco de nuestro sistema patriarcal, y los valores masculinos siguen teniendo una mayor consideración social que los femeninos también en el mundo del deporte. Los parámetros masculinos y femeninos son construcciones sociales y por lo tanto objeto de transformación en cada momento. Berger y Luckmann (1993) lo reflejan claramente en su modelo teórico de la construcción social, al decir que en ella destacan los valores, actitudes y comportamientos para 
llevar a cabo la distinción entre hombres y mujeres. De tal modo que los valores masculinos han tenido y tienen mayor prestigio social y por ello son los que actualmente se han mantenido como modelo de actuación (competitividad, éxito, lucha, sacrificio, fuerza, vigor, etc.). Lo que percibimos como realidad social es algo que la propia sociedad ha ido construyendo por medio de los grupos humanos de los que formamos parte. En este proceso intervienen tres aspectos interrelacionados que se pueden aplicar a la realidad deportiva femenina: la objetivación histórica, la interiorización y la exteriorización institucionalizada.

En la misma línea se muestran Puig y Mosquera (2009: 104) cuando señalan que "tanto el significado de la competición como la estructura del tiempo resultan poco atractivas para muchas mujeres que en el momento de acceder al ámbito deportivo, se decantan por actividades más próximas a los valores y hábitos adquiridos durante el proceso de socialización".

Esta realidad no sólo ocurre entre los círculos ajenos al deporte, ya que entre los propios implicados en las distintas dimensiones deportivas, también podemos encontrar muchas expresiones estereotipadas desde el punto de vista del género, tanto por parte de los hombres como de las mujeres (Pujadas, 2010). Esto es lo que incrementa de forma intensa la fuerza para que los estereotipos sean tan resistentes al cambio.

El lenguaje es un instrumento que no sólo es importante por la información y comunicación que facilita, sino también por la transmisión de valores, los cuales sirven para ver y analizar las cosas de una manera u otra. Las palabras y los mensajes están dotados de significados que pueden ser utilizados para modificar o perpetuar determinadas situaciones de dominio. Siguiendo a Bauman (2000), en una sociedad individualista, transitoria e imprevisible como la actual, donde la modernidad líquida está representada por identidades cada vez más flexibles y moldeables, el lenguaje adquiere una influencia y un poder desmesurado como para no darle la importancia que requiere.

Tanto en el lenguaje escrito como en el lenguaje verbal se utilizan términos masculinos con connotaciones incluso referidas a sus atributos como formas de motivación en las acciones que realizan ( si queréis ganar, hay que echarle....!), mientras que el uso de términos femeninos queda relegado al uso de refuerzos negativos (ijugáis como nenas!), (Alfaro, Bengoechea y Vázquez, 2010). Pero, incluso hay ocasiones en las que se utilizan las mismas expresiones masculinizadas cuando van dirigidas a las propias deportistas o entrenadoras, por eso el grado de interiorización en la mayoría de la población es tan fuerte. 
Por otro lado, el lenguaje icónico también ha alcanzado unos niveles muy elevados de popularización y espectacularidad, que no ha hecho más que incentivar el tratamiento de la información y la imagen deportiva femenina hacia el lado de la desigualdad. Así lo recocía ya Cagigal (1981: 296) al decir que el hombre contemporáneo necesitaba del movimiento y el aliciente cinético, y su consecución la obtenía sin tener en cuenta la calidad, simplemente con la información visual. Por eso interpretaba este hecho cultural como un síntoma deficitario en la calidad de vida de una sociedad.

Este lenguaje traspasa todo tipo de barreras relacionadas con los idiomas, se transmite con una gran rapidez, es más espontáneo y directo, y es compartido por un mayor número de personas que otro tipo de lenguaje. Cualquier imagen es fácilmente comprensible para los diferentes colectivos de individuos porque las reglas por las que se rigen todos, son compartidas en todos los lugares del mundo (Gil y Cáceres, 2008). Por eso se hace imprescindible, como destaca Molina (2013), utilizar el pensamiento crítico para analizar este tema, ya que así evitaremos caer en estigmas y propuestas estereotipadas.

Del mismo modo que debemos aplicarlo a las fuentes de información que los medios de comunicación social utilizan, ya que, al conceder primacía a dichos intereses, pueden llegar a distorsionar la realidad o a no plasmarla de forma objetiva y precisa. En los medios de comunicación parece que el deporte practicado por los hombres es el que tiene todo el protagonismo y la exclusividad informativa. Aunque referido al rugby, pero extensivo a otros deportes como expone Martín Horcajo (2006), muy pocas veces tanto en espacio como en tiempo se reconocen y se informan los logros alcanzados por las mujeres deportistas.

\section{Conclusiones y propuestas}

En la actualidad y siguiendo los estudios realizados por García Ferrando (2009) se ha producido un gran avance en la igualdad de oportunidades para la práctica deportiva desde el mundo de la mujer, pero también es cierto que no se puede aún reconocer la existencia de una equidad con respecto a los hombres. Esto queda plasmado cuando las mujeres consiguen logros tan importantes como los hombres y sin embargo, no reciben los mismos elogios, las mismas compensaciones económicas ni ocupan grandes titulares en los medios de comunicación. Los resultados arrojan cifras en las que éstos continúan realizando más actividades deportivas, hay 
más deportistas en todos los niveles y el abanico de modalidades deportivas que practican los hombres sigue siendo mucho mayor (García Ferrando, 2009: 50).

Después de haber analizado los distintos factores que han incidido de forma excluyente en la educación física y en la práctica deportiva femenina, creemos necesario plasmar una serie de propuestas que favorezcan la igualdad y minimicen las diferencias de género en el contexto deportivo en general:

- Establecer nuevas medidas normativas para superar situaciones de desigualdad, sobre todo, para tener realmente las mismas oportunidades en disciplinas deportivas que han sido tradicionalmente diseñadas según los parámetros físicos predominantes en los hombres.

- Consensuar entre los agentes sociales que intervienen en el proceso de socialización deportiva una serie de medidas pedagógicas aplicadas al deporte de base, donde si se trabajan equitativamente los modelos sociales educativos y deportivos para los niños y niñas, cabría esperar que esto se mantuviera durante la etapa adulta.

- Cuidar las imágenes, las expresiones, los conceptos y los estereotipos sexistas que se vienen utilizando de forma sistemática en los medios de comunicación y campañas publicitarias vinculadas al deporte.

- Dar a conocer las sugerencias emitidas por organismos como la UNESCO, el Consejo de Europa, el Parlamento Europeo y los diversos organismos de igualdad españoles para visibilizar a las mujeres y evitar el trato y el lenguaje sexista en el ámbito deportivo.

A modo de conclusión, se puede considerar, que debemos ser conscientes de que en el deporte influyen múltiples condicionantes culturales, sociales, económicos y políticos que requieren de tiempo para que los colectivos sociales implicados trabajen y ayuden a modificar muchas tradiciones culturales y deportivas que impregnan el mundo deportivo. Pero al mismo tiempo, resulta muy importante tener en cuenta las posibilidades que ofrece el deporte como agente de socialización y utilizarlo con el fin de eliminar estereotipos y actitudes prejuiciales, que obstaculizan en muchas ocasiones el desarrollo de las personas, así como sus posibilidades y expectativas. 


\section{BIBLIOGRAFÍA}

- Águila, Cornelio (2008): "Imágenes y discurso del deporte contemporáneo: desafíos para una socialización democrática desde la edad escolar”. En: Irene Hernández, Luis F. Martínez y Cornelio Águila (eds.): El deporte escolar en la sociedad contemporánea. Almería: Universidad de Almería, pp. 17-60.

- Alfaro, Élida; Bengoechea, Mercedes y Vázquez, Benilde (2010): Hablamos de deporte. En femenino y en masculino. Madrid: Instituto de la mujer.

- Bauman, Zygmunt (2000): Modernidad Líquida. Buenos Aires: F.C.E.

- Berger, Peter y Luckmann, Thomas (1993): La construcción de la realidad social. Buenos Aires: Amorrortu.

- Blanchard, Kendall y Cheska, Alyce (1986): Antropología del deporte. Barcelona: Ediciones Bellaterra.

- Blández, Julia; Fernández, Emilia y Sierra, Miguel A. (2007): "Estereotipos de género, actividad física y escuela: la perspectiva del alumnado". En: Profesorado. Revista de curriculum y formación del profesorado, vol. 10, $\mathrm{n}^{\mathrm{o}}$ 2, [en línea] Disponible en: http://www.ugr.es/ recfpro/rev112ART5.pdf [02/01/2014].

- Bourdieu, Pierre (1988): Cosas dichas. Buenos Aires: Gedisa.

- Buitrón, César y Del Riego, Carlos (2004): Citius, Altius, Fortius. Las Olimpiadas y sus mitos. León: Everest.

- Cagigal, Jose María (1981): ¡Oh Deporte ;. Anatomía de un gigante. Valladolid: Miñón.

- Cascón, Antonio. (2005): "Educación y política: el deporte en la sociedad antigua". En: Fernando García Romero y Berta Hernández García (eds.): In corpore sano. El deporte en la Antigüedad y la creación del moderno olimpismo. Madrid: Delegación de Madrid de la Sociedad de Estudios Clásico, pp. 155-176.

- Caspistegui, Francisco Javier (2006): “De la marginación a la práctica: mujer y deporte en la primera mitad del siglo XX”. En: Vasconia, n 35, pp. 253-269.

- Díez García, Alejandro (2006): Evolución histórica y social de la presencia de la mujer en la práctica física y el deporte. Revista Lecturas Educación Física y Deportes, no 99, [en línea] http://www.efdeportes.com/efd99/mujer.htm [02/01/2014]. 
- Díez Mintegui, Carmen (1996): "Deporte y construcción de las relaciones de género”. En: Gazeta de Antropología, $\mathrm{n}^{\mathrm{o}}$ 12, [en línea] Disponible en http://www.ugr.es/ pwlac/G12_10Carmen_Diez_Mintegui.html [02/01/2014].

- García de León, Ma Antonia; García de Cortázar, Marisa y Ortega, Félix (1996): Sociología de las mujeres españolas. Madrid: Editorial Complutense.

- García Ferrando, Manuel (2006): Posmodernidad y deporte: entre la individualización y la masificación. Encuesta de hábitos deportivos de los españoles. Madrid, Alianza.

- García Ferrando, Manuel, Puig, Nuria y Lagardera Francisco (2009): Sociología del deporte. Madrid: Alianza.

- García Manso, Juan Manuel (2010): "La mujer en los juegos olímpicos de la era moderna”. En: Luis Solar (ed.): De Re Olímpica. San Sebastián: Centro de Estudios Olímpicos EHU/UPV, pp. 137-178.

- García Romero, Fernando (1992): Los Juegos Olímpicos y el deporte en Grecia. Sabadell: Ausa.

(2005): “Mujer y deporte en el mundo antiguo". En: Fernando García Romero y Berta Hernández García (eds.): Corpore sano. El deporte en la Antigüedad y la creación del moderno olimpismo. Madrid: Delegación de Madrid de la Sociedad de Estudios Clásico, pp. 177-204.

- Gil, Marta y Cáceres, Juanjo (2008): Cuerpos que hablan: género, identidades y representaciones sociales. Barcelona: Montesinos.

- Léséleuc, Eric; Athanasios, Pappous y Maecellini, Anne (2009): “La cobertura mediática de las mujeres deportistas con discapacidad. Análisis de la prensa diaria de cuatro países europeos durante los Juegos Paralímpicos de Sydney 2000”. En: Apunts. Educación Física y Deportes, no 97, pp. 80-88.

- Malissard, Alain (1996): Los romanos y el agua. Barcelona: Herder.

- Manrique, Juan Carlos; Torrego, Luis, López, Víctor y Monjas, Roberto (2009): "Factores que determinaron una educación física y deportiva de género durante el franquismo". En: Apunts. Educación física y deportiva, no 98, pp. 5-14. 
- Martín Horcajo, Montserrat (2006): “Contribución del feminismo de la diferencia sexual a los análisis de género en el deporte”. En: Revista Internacional de Sociología, $\mathrm{n}^{\circ}$ 44, mayoagosto, pp. 111-131.

- Molina, Gerardo (2013): Sociología del fenómeno deportivo. Claves para prácticas responsables sociales y educativas. Madrid: Librerías Deportivas Esteban Sanz.

- Moran, Caitlin. (2013): Cómo ser mujer. Barcelona: Anagrama.

- Mosquera, Ma José y Puig, Nuria (2009): “Género y edad en el deporte. En: Manuel García Ferrando, Nuria Puig y Francisco Lagardera (comps.): Sociología del deporte. Madrid: Alianza, pp.99-125.

- Pastor, Mauricio y Aguilera, Jose Luis (2007):“La mujer y el deporte en la antigüedad clásica”. En Mauricio Pastor, Miguel Villena y Jose Luis Aguilera (eds.): Deporte y Olimpismo. Granada: Universidad de Granada, pp. 33-52.

- Pérez Triviño, Jose Luis (2011): Ética y deporte. Bilbao: Desclée De Brouwer.

- Pujadas, Xavier (2010) (coord.): La metamorfosis del deporte. Investigaciones sociales y culturales del fenómeno deportivo contemporáneo. Barcelona: Editorial UOC.

- Ramírez, Gonzalo y Piedra, Joaquín (2011): “Análisis de la obra de Jose María Cagigal en relación con el concepto de mujer y su inclusión en el deporte”. En: Apunts. Educación física y deportiva, $\mathrm{n}^{\mathrm{o}} 105$, pp. 67-72.

- Ruiz Tendero, Germán (2011): "Hábitos de práctica lúdica y deportiva en niños y niñas en edad escolar: un estudio transversal”. En: EmásF. Revista digital de Educación Física, nº 10, 17-31.

- Santos, Antonio y Balibrea, Enriqueta (2004): "Deporte, mujer y exclusión social. Experiencias europeas de inserción a través del deporte". En Antón Álvarez Sousa (coord.): Turismo, ocio y deporte: VIII Congreso Español de Sociología: transformaciones globales: confianza y riesgo. A Coruña: Universidad de A Coruña. Servicio de Publicaciones, pp. 413424.

- Zagalaz, María Luisa (2001): "La educación física femenina durante el franquismo. La sección femenina". En Apunts. Educación física y deportiva, nº 65, pp. 6-16. 